\title{
Teachers' Opinions Concerning Microteachings as a Training Technique: A Case Study from ASPETE, Greece
}

\author{
Koutsoukos Marios ${ }^{1}$, Fragoulis Iosif ${ }^{2}$ \\ ${ }^{1}$ School of Pedagogical and Technological Education ASPETE, Kozani, Greece \\ ${ }^{2}$ School of Pedagogical and Technological Education ASPETE, Heraklion, Greece \\ Correspondence: Marios Koutsoukos, School of Pedagogical and Technological Education ASPETE, Kozani, Greece.
}

Received: August 29, 2016

doi:10.11114/jets.v4i11.1843
Accepted: September 18, $2016 \quad$ Online Published: September 26, 2016

URL: http://dx.doi.org/10.11114/jets.v4i11.1843

\begin{abstract}
The main objective of the present research is to investigate teachers' opinions concerning microteachings as a training technique. For research purposes, a case study was conducted, studying a sample of secondary education teachers in the School of Pedagogical and Technological Education (ASPETE) in Kozani, Greece. Among the research's main findings is teachers' belief that microteachings serve as a beneficial tool which helps them improve their teaching skills, having also a significant effect on various aspects of teaching.
\end{abstract}

Keywords: microteaching, teachers' opinions, case study, ASPETE, Greece

\section{Introduction}

Microteaching is a teacher training technique whereby a trainee teacher prepares and practices a certain lesson in a ten or fifteen minute session, which is often videotaped, aiming at getting constructive feedback from a supervising professor and other trainee teachers (Remesh, 2012; Fernandez \& Robinson, 2006). This teacher training tool was developed and applied by the School of Education at Stanford University in 1963, in order to serve as a useful tool for preliminary experience and practice in teaching (Allen, 1967). Since then, microteaching has been used to develop preservice teachers as well as experienced teachers in various forms of education and nowadays is a technique practiced worldwide, providing teachers an opportunity to upgrade their skills (Remesh, 2012; Mergler \& Tangen, 2010).

It is widely accepted that microteaching, as a teachers' training technique, has significant advantages-benefits for teachers involved in this procedure (Amobi \& Irwin, 2009; Popovich \& Katz, 2009; Fernandez \& Robinson, 2006). More specifically, microteaching gives the opportunity to practice skills under controlled conditions in a safe and supportive environment (Amobi \& Irwin, 2009). It is a practice which is scaled down in terms of teaching time, learning content and number of students involved (Slabbert, 2002). Thus, teachers are not confronted with preparing a lesson plan of forty or forty five minutes in length, nor do they have to worry about the management of a relatively large group of twenty or thirty students (Allen, 1967).

Moreover, microteachings allow teachers to practice effectively certain skills and apply experiential and collaborative teaching techniques before they are confronted with more complex real classroom situations (Ralph, 2014; Slabbert, 2002). Thus, teachers are given the opportunity to apply under controlled circumstances, techniques such as brainstorming, group discussion, role playing, experiment and simulation. Practicing under controlled circumstances and taking into consideration relatively limited variables, teachers, especially inexperienced ones, can easily correct problems or errors that may arise during the application of these techniques.

Another notable advantage is the immediate feedback which is provided after each practice session as microteachings are videotaped (Remesh, 2012). More particularly, teachers who hav completed a microteaching have the opportunity to view the videotape of the lesson taught, getting at the same time valuable feedback from the supervising professor and peers in the microteaching group (Yamamoto \& Hichs, 2008; Benton-Kupper, 2001). As a result, the viewing of the videotaped microteaching along with the discussion followed, points out the strengths and weaknesses of each case. Often, feedback is provided orally and in written forms developed for this purpose, focusing on what has worked and what improvements can be made to each microteaching (Kilic, 2010; Amobi \& Irwin, 2009; Benton-Kupper, 2001). The feedback provided by the videotaped lesson and by the group's comments, helps teacher-trainees to improve their 
teaching skills as it serves as a source of encouragement and motivation for more practice and improvement (Mergler \& Tangen, 2010; Slabbert, 2002; Kpanja, 2001).

Apart from the obvious advantages, the microteaching procedure has also some disadvantages. More specifically, maybe the most commonly perceived deficiency is artificiality, as microteaching takes place in an artificially created environment which not simulates exactly real-life classroom situation (He \& Yan, 2011). In particular, the number of virtual students participating is small, usually up to eight persons, so is easy to manage, keeping discipline problems to a minimum (Slabbert, 2002). As a result, microteaching seems to some extent limit pre-service teachers' development of real-life classroom teaching competence (He \& Yan, 2011).

Another disadvantage lies in the peers who act as virtual pupils in the microteaching group. More particularly, peers can easily become bored with the micro lesson's content, especially if they have foreknowledge of a learning subject or if they are from various specialties and are not familiar at all with the content (Slabbert, 2002). In addition, in some cases peers may be reluctant to critique sincerely, comment and provide feedback to fellow students (Slabbert, 2002).

Nevertheless, microteaching is a useful training tool which gives teachers the opportunity to bridge the gap between theory and practice. In any case, this useful tool needs to be viewed as an integral part of a complete teacher training program, functioning always within this context (Slabbert, 2002). Thus, provided that it is implemented appropriately, microteaching can be a beneficial learning experience (Ralph, 2014).

In Greece, the main teacher training institution at tertiary level is the School of Pedagogical and Technological Education (in Greek ASPETE), which is situated in Athens, operating also branches in ten more cities across the country (Thessaloniki, Patras, Ioannina, Volos, Heraklion Crete, Sapes, Kozani, Mytilene, Rhodes and Argos). ASPETE offers one year program of pedagogical training (in Greek EPPAIK), which includes theoretical lessons as well as practical exercises and microteachings.

In particular, as far as microteachings are concerned, in the first semester of the program, every participant has to prepare the teaching of two well organized micro lessons of fifteen minutes each. These micro lessons are presented to five or six fellow students who act as "pupils", under the guidance of a supervising professor. Microteachings are videotaped and after the micro lesson is completed, the entire record or selected parts of it are replayed in the presence of the teacher, fellow students and the supervising professor.

In addition, the supervisor professor has to complete an evaluation form which scores in 100 and contributes to the identifying and mentioning of the microteaching's strengths and weaknesses. The evaluation form takes into consideration certain criteria such as: appropriate lesson planning, clarity of presentation, interaction with pupils, application of collaborative teaching techniques, classroom management and efficient use of teaching time. If a microteaching does not satisfy the criteria desired and its score is $<50$, the teacher is given the opportunity to plan and present again the micro-lesson in another scheduled microteaching. Two microteachings take place also in the second semester, following the same procedure described above. The only difference is the amount of teaching time which is increased to twenty minutes for each micro lesson.

Each micro lesson is accompanied by a written lesson plan which serves as the teacher's step by step guide for completing successfully a particular lesson. A well-developed lesson plan is "the instructor's road map of what students need to learn and how it will be done effectively during the class time" (Milkova, 2016). More specifically, a lesson plan includes: the lesson's topic, a list of learning goals (objectives), the lesson's timeline, teaching techniques and learning strategies, a list of required materials, resources and references (Fink, 2003). There are many formats for a lesson plan and ASPETE uses a particular template which includes the elements mentioned above.

\section{Method}

The main purpose of the present research was to investigate teachers' opinions concerning microteachings as a training technique, exploring to what extent it proved to be a beneficial procedure. Moreover, further objectives were to investigate opinions about microteaching's effect on various aspects of modern teaching and to examine the role of videotaping in the whole procedure.

For the research's purpose, the case study method was chosen, along with a relatively small and deliberately selected sample of teachers who completed the one year program of pedagogical training during the academic year 2015-2016 in the ASPETE branch of Kozani, Western Macedonia. Research was carried out on completion of the program and more specifically in June 2016, so that teachers would have completed all theoretical lessons and microteachings.

More specifically, a combination of qualitative and quantitative research was carried out in order to provide a thorough study of the main parameters of the issue. Firstly, six qualitative semi structured interviews took place aiming at uncovering opinions, recording viewpoints and producing at the same time an in depth understanding not easily achieved with the use of quantitative methods. In addition, the interviews aimed at highlighting key points and 
determining the conceptual axes of the questionnaire to be applicable later for the phase of quantitative research. The interviews were tape recorded and had an average duration of 35 minutes and contributed to the clarification of variables used later at the quantitative stage of the research. It should be noted that focused qualitative research was also carried out after the quantitative, in order to unveil and clarify certain points.

Then, taking into consideration the conclusions derived from the qualitative research, a brief printed questionnaire was used, designed in compliance with the research objectives and the relevant literature review. It is widely acknowledged that the questionnaire is a useful tool which is often used in social science research as its results can be easily quantified. A total of 86 questionnaires were handed out, of which 82 were returned with a high response rate (95.3\%) and SPSS 17 software package was used for the statistical analysis of the questionnaires.

\section{Results}

The interviews which took place in the qualitative phase of the research indicated that microteachings proved to be a beneficial training situation for ASPETE students. Although this situation at first was strange and full of anxiety for the majority of the students, the valuable feedback provided at the end, promoted the improvement of skills such as lesson planning, teaching time management, interaction between teacher and students, use of experiential teaching techniques and classroom management skills.

Furthermore, qualitative interviews demonstrated that self-critique of videotaped microteaching can also provide useful feedback. Also, it should be noted that all participants who were interviewed, expressed the opinion that microteaching is a necessary situation before being placed in a school for teaching in real classrooms. Finally, another factor highlighted in the qualitative findings of this study, is some participants' suggestion that the duration of fifteen minutes length for each microteaching is rather short, as it seems to be difficult to fit some lesson concepts into this teaching time.

As far as results from the quantitative research are concerned, statistical analysis of the questionnaires initially focused on outlining the respondents' profile. Thus, out of the 82 teachers, 43 were female (52.4\%) and 39 male (47.6\%). As far as age distribution is concerned, the majority of teachers, 48 out the $82(58.5 \%)$ were between $31-40$ years old, while 21 of the respondents were between 21-30 (25.6\%) and 11 respondents were between 41-50 (13.4\%). Finally, only two of the teachers were over 51 years old (Table 1). Regarding postgraduate studies, 36 teachers $(43.9 \%)$ held a master degree while 46 teachers had no postgraduate studies at the time the present research was carried out.

It should be noted that the vast majority of the participants, 71 out of 82 , had no previous experience of microteaching training $(86.6 \%)$ while only 11 of them $(13.4 \%)$ had practiced microteachings before (Table 1). Focused qualitative interviews which took place after the quantitative research indicated that out of these 11 teachers, 6 of them had practiced microteachings during their postgraduate studies in Hellenic Open University while 5 of them had practiced microteachings in other training programs they had previously participated.

Next, focusing on the respondents' teaching experience, at the time of the research, 31 of the respondents (37.8\%) had no previous experience in secondary education, while 20 of the respondents $(24.4 \%)$ had teaching experience of $1-5$ years, 18 out of the $82(22 \%)$ had 6-10 years of experience and 13 out of the 82 had teaching experience of over 10 years in secondary education (Table 1 ).

Table 1. Teachers' profile

\begin{tabular}{lccccc}
\hline Sex & \multicolumn{3}{l}{ Male - Female } & Total \\
& 39 & 42 & & 82 \\
\hline Age & $21-30$, & $31-40$, & $41-50$, & $>51$ & \\
& 21 & 48 & 11 & 2 & 82 \\
Postgraduate Studies & Yes & No & & \\
& 36 & 46 & & 82 \\
Previous Training in & Yes & No & & 82 \\
Microteachings & 11 & 71 & & \\
Years teaching in & 0 & $1-5$ & $6-10$ & $>10$ & 82 \\
Secondary Education & 31 & 20 & 18 & 13 & 82 \\
\hline
\end{tabular}

Next, using a five-point Likert-type scale (Vagias, 2006) ranging from "not at all beneficial" to "very beneficial", teachers were asked to demarcate to what extent microteachings were beneficial in improving their teaching skills. The vast majority of the participants, 66 out of $82(80.5 \%)$, claimed that microteachings proved to be very beneficial in improving their teaching skills while 16 teachers (19.5\%) defined microteachings' effect as beneficial (Table 2). This finding is in accordance to literature review (Ralph, 2014; Remesh, 2012; Mergler \& Tangen, 2010; Fernandez, 2005) and indicates the importance of microteaching as a useful tool for teacher training. 
Table 2. How beneficial were microteachings according to teacher-participants in improving their teaching skills

\begin{tabular}{cccccc}
\hline Not at all beneficial & Not Very beneficial & Moderately beneficial & Beneficial & Very beneficial & Total \\
\hline 0 & 0 & 0 & 16 & 66 & 82 \\
\hline
\end{tabular}

In addition, participants in this case study were asked to demarcate to what extent videotaping was useful in the microteaching situation. The majority of the respondents, 59 out of 82 (72\%), claimed that videotaping proved to be very useful, 18 teachers claimed it was a useful procedure, while 5 of them expressed the opinion that videotaping was moderately useful (Table 3).

Table 3. How useful was microteaching's videotaping according to teacher-participants in providing feedback

\begin{tabular}{cccccc}
\hline Not at all useful & Not Very useful & Moderately useful & Useful & Very useful & Total \\
\hline 0 & 0 & 5 & 18 & 59 & 82 \\
\hline
\end{tabular}

Finally, respondents were asked to evaluate the significance of microteachings' effect on certain aspects of teaching. In other words, teachers recorded to what extent microteachings helped them improve basic skills, necessary to modern teaching. Bearing in mind the conclusions of the qualitative research and also the literature review (Saban \& Çoklar, 2013; Amobi \& Irwin, 2009; Fernandez \& Robinson, 2006), the present case study focused on five main aspects: lesson planning, teaching time management, verbal and non-verbal interaction, classroom management skills and use of experiential teaching techniques.

More particularly, as far as lesson planning is concerned, the vast majority of the respondents, 76 out of 82 (92.7\%) indicated that microteachings' effect is very significant to this procedure, 5 of the respondents $(6 \%)$ defined the effect as "significant" while only one respondent defined it as "moderately significant" (Table 4). Another critical parameter in teacher training is the management of teaching time. According to 70 participants in this research (85.3\%), microteachings' effect is very significant on this parameter, as practice through microteachings helps teachers to become familiar with time management (Table 4).

Effective verbal and non-verbal interaction between teacher and students is a key factor in modern teaching. As indicated below (Table 4$), 68$ teachers $(82.9 \%)$ believe that microteachings have a very significant effect on this parameter, as they enhance teachers' ability to interact successfully. Another important aspect in modern education is the use of experiential teaching techniques which actively engage students and make the learning procedure more student-centered. The majority of the respondents, 64 out of $82(78 \%)$, believe that practice acquired through microteachings has a very significant effect on the use of experiential teaching techniques.

Finally, classroom management is another crucial aspect of modern teaching, as it is strongly related to the formation of an appealing and creative learning climate. Microteachings offer the opportunity to practice classroom management skills in a safe but artificially created environment. According to 60 respondents $(73.2 \%)$, microteachings' effect is very significant, according to 14 respondents $(17 \%)$ is significant and according to 5 respondents $(6.1 \%)$ moderately significant. On the other hand, 3 respondents $(3.6 \%)$ believe that microteachings have not a very significant effect on classroom management skills.

Table 4. The significance of microteachings' effect on various aspects of teaching

\begin{tabular}{|c|c|c|c|c|c|c|}
\hline Aspect & $\begin{array}{l}\text { Not at all } \\
\text { significant }\end{array}$ & $\begin{array}{c}\text { Not Very } \\
\text { significant }\end{array}$ & $\begin{array}{c}\text { Moderately } \\
\text { significant }\end{array}$ & Significant & $\begin{array}{c}\text { Very } \\
\text { significant }\end{array}$ & Total \\
\hline Lesson planning & 0 & 0 & 1 & 5 & 76 & 82 \\
\hline Teaching time management & 0 & 0 & 0 & 12 & 70 & 82 \\
\hline $\begin{array}{l}\text { Verbal and non-verbal } \\
\text { interaction }\end{array}$ & 0 & 0 & 1 & 13 & 68 & 82 \\
\hline $\begin{array}{l}\text { Use of experiential teaching } \\
\text { techniques }\end{array}$ & 0 & 1 & 6 & 11 & 64 & 82 \\
\hline Classroom management skills & 0 & 3 & 5 & 14 & 60 & 82 \\
\hline
\end{tabular}

\section{Discussion}

Nowadays, it is widely accepted that microteaching is a useful tool which can play an important role in teachers' training worldwide, offering outstanding possibilities to fill the gap between theory and practice in traditional teacher education (Ralph, 2014; Mergler \& Tangen, 2010; Slabbert, 2002). The research presented in this case study confirms previous research findings regarding the benefits of the microteaching technique in assisting teachers to develop their skills (Ralph, 2014; Chatzidimou, 2011; Amobi \& Irwin, 2009). Provided that it is implemented appropriately, microteaching can become an effective and constructive learning experience, for both pre-service and in-service teachers.

As noted above, the vast majority of the teachers participating at this research had no previous experience at microteachings. Results from qualitative and quantitative research highlight the significance of microteachings, as the feedback given through this procedure enhanced teaching skills such as lesson planning, teaching time management, 
verbal and non-verbal interaction, use of experiential teaching techniques and classroom management ability.

Videotaping of the microteaching seems to be another important parameter which contributes to this feedback. Empirical evidence from ASPETE demonstrated that videotaping, along with discussion and comments from the supervisor professor and peers in the microteaching group, proved to be a key factor to the whole procedure, giving the opportunity for self-improvement.

The present research builds on the understanding of microteachings as a training technique and advances knowledge about teachers' opinions concerning this useful training tool. Although research results based on case studies sometimes offer limited generalizability, in social sciences the case study method in general can certainly contribute to the cumulative development of knowledge (Flyvbjerg, 2014). As far as practical implications are concerned, the present research offers insights for teachers, adult educators, mentors and researchers in the field of teacher training and provides a starting point for future research on various aspects of this issue. As nowadays teacher training seems to be a crucial factor in modern education, research on microteachings' role can offer valuable insights into how teachers can improve their various skills, becoming more and more effective in everyday classroom teaching.

\section{Acknowledgements}

The authors would like to thank the 82 respondent teachers for their cooperation and willingness to participate to the present research. Also, the authors would like to thank the editor and the reviewers of this journal for their valuable comments on an earlier version of this manuscript.

\section{References}

Allen, D. W. (1967). Microteaching, a description. Stanford University, California

Amobi, F., \& Irwin, L. (2009). Implementing on-campus microteaching to elicit preservice teachers' reflection on teaching actions: Fresh perspective on an established practice. Journal of the Scholarship of Teaching and Learning, 9(1), 27-34.

Benton-Kupper, J. (2001). The Microteaching experience: Students' perspectives. Education, 121(4), 830-835.

Chatzidimou, K. (2011). Microteaching, a "Middle-Aged" Educational Innovation: Still in Fashion? The Future of Education, International Conference.

http://conference.pixelonline.net/edu_future/common/download/Paper_pdf/SOE15-Chatzidimou.pdf

Fernandez, M. (2005). Learning through Microteaching Lesson Study in Teacher Preparation. Action in Teacher Education, 26(4), 37-47. http://dx.doi.org/10.1080/01626620.2005.10463341

Fernandez, M., \& Robinson, M. (2006). Prospective Teachers' Perspectives on Microteaching Lesson Study. Education, 127(2), 203-215.

Fink, D. L. (2003). Creating Significant Learning Experiences: An Integrated Approach to Designing College Courses. San Francisco: Jossey-Bass.

Flyvbjerg, B. (2014). Five misunderstandings about case-study research. In C. Seale, G. Gobo, J. Gubrium \& D. Silverman (eds.), Qualitative Reseach Practice (pp.420-434). London and Thousand Oaks, Sage. http://dx.doi.org/10.4135/9781473915480.n40

He, C., \& Yan, C. (2011). Exploring authenticity of microteaching in pre-service teacher education programmes. Teaching Education, 22(3), 291-302. http://dx.doi.org/10.1080/10476210.2011.590588

Kilic, A. (2010). Learner-centered Micro Teaching in Teacher Education. International Journal of Instruction, 3(1), 77-100.

Kpanja, E. (2001). A study of the effects of video tape recording in microteaching training. British Journal of Educational Technology, 32(4), 483-486. http://dx.doi.org/10.1111/1467-8535.00215

Mergler, A., \& Tangen, D. (2010). Using microteaching to enhance teacher efficacy in preservice teachers. Teaching Education, 21(2), 199-210. http://dx.doi.org/10.1080/10476210902998466

Milkova, S. (2016). Strategies for Effective Lesson Planning. Center for Research on Learning and Teaching, University of Michigan. Retrieved from: http://crlt.umich.edu/gsis/p2_5

Peker, M. (2009). The use of expanded microteaching for reducing preservice teachers' teaching anxiety about mathematics. Scientific Research and Essay, 4(9), 872-880.

Popovich, N. G., \& Katz, N. L. (2009). A Microteaching Exercise to develop performance-based abilities in Pharmacy students. American Journal of Pharmaceutical Education, 73(4), 1-8. http://dx.doi.org/10.5688/aj730473 
Ralph, E. (2014). The Effectiveness of Microteaching: Five Years' Findings. International Journal of Humanities Social Sciences and Education, 1(7), 17-28.

Remesh, A. (2012). Microteaching, an efficient technique for learning effective teaching. Journal of Research in Medical Sciences, 18(2), 158-163.

Saban, A., \& Çoklar, N. (2013). Pre-Service teachers' opinions about the Micro-Teaching method in teaching practice classes. The Turkish Online Journal of Educational Technology, 12(2), 234-241.

Slabbert, J. A. (2002). Microteaching in: Basson, N., Oosthuizen, W., Duvenage, D. \& Slabbert, J. Johannesburg: Juta and $\mathrm{Kie}$

Vagias, W. M. (2006). Likert-type scale response anchors. Clemson International Institute for Tourism \& Research Development, Department of Parks, Recreation and Tourism Management. Clemson University.

Yamamoto, J., \& Hichs, J. (2008). Digitalizing microteaching. The Field Experience Journal, 2(3), 1-16.

\section{$(\mathrm{Cc}) \mathrm{BY}$}

This work is licensed under a Creative Commons Attribution 3.0 License. 